http://ojs.stikes-muhammadiyahku.ac.id/index.php/herbapharma

\title{
UJI STABILITAS HERBAL JELLY DRINK EKSTRAK BIJI ALPUKAT (Persea americana Mill.) DAN DAUN SALAM (Syzygium polyanthum (Wight) Walp.)
}

Nisa Puspita Trisnasary, Ahmad Wildhan Wisnu Wardaya

Program Studi Farmasi, STIKes Muhammadiyah Kuningan

*E-mail : nisapt118@gmail.com

\begin{abstract}
ABSTRAK
Kandungan yang terdapat pada ekstrak biji alpukat dan daun salam adalah senyawa tanin dan flavonoid yang berkhasiat sebagai antioksidan alami yang dapat mengontrol dan menurunkan kadar glukosa darah. Penelitian ini bertujuan untuk membuat sediaan herbal jelly drink campuran ekstrak biji alpukat dan daun salam yang memiliki tekstur, konsistensi serta stabilitas yang baik. Metode yang digunakan yaitu metode eksperimental laboratorium, dibuat sediaan jelly drink dengan berbagai konsentrasi karagenan $(0,20 \% ; 0,30 \%$; dan $0,40 \%)$. Parameter pengujian meliputi uji stabilitas pada suhu sejuk (5-15ㅇ), suhu kamar $\left(25^{\left.-30^{\circ} \mathrm{C}\right)}\right.$ ), dan suhu panas $\left(40-45^{\circ} \mathrm{C}\right)$ selama 21 hari meliputi pengamatan sineresis, $\mathrm{pH}$, dan organoleptik. Hasil menunjukkan konsentrasi karagenan 0,30\% membentuk jelly dengan tekstur dan konsistensi baik. Pada suhu sejuk, sineresis $2 \%, \mathrm{pH} 6$, dan organoleptik (warna coklat, tekstur kenyal, aroma khas). Pada suhu kamar sineresis $4 \%, \mathrm{pH} 5$, dan organoleptik (warna coklat gelap, tekstur sedikit cair, aroma tidak sedap menyengat). Pada suhu panas sineresis $8 \%$, pH 6 , dan organoleptik (warna coklat, tekstur sedikit kenyal, aroma tidak sedap). Kesimpulan stabilitas paling baik disimpan pada suhu sejuk $\left(5-15^{\circ} \mathrm{C}\right)$ dengan tingkat sineresis $2 \%, \mathrm{pH} 6$, dan organoleptik meliputi warna coklat, tekstur kenyal dan aroma yang khas.
\end{abstract}

Kata Kunci: Biji alpukat, daun salam, jelly drink, stabilitas.

\begin{abstract}
The content contained in avocado seed extract and bay leaves are tannin compounds and flavonoids that are efficacious as natural antioxidants that can control and lower blood glucose levels. This study aims to make herbal jelly drink preparations a mixture of avocado seed extract and bay leaves that have a good texture, consistency and stability. The method used is a laboratory experimental method, made jelly drink preparations with various concentrations of caragenan (0.20\%; 0.30\%; and 0.40\%). Testing parameters include stability tests at cool temperatures $\left(5-15^{\circ} \mathrm{C}\right)$, room temperature $\left(25-30^{\circ} \mathrm{C}\right)$, and hot temperatures $\left(40-45^{\circ} \mathrm{C}\right)$ for 21 days including observation of syneresis, $\mathrm{pH}$, and organoleptics. The results showed a karagenan concentration of $0.30 \%$ forming a jelly with good texture and consistency. At cool temperatures, syneresis $2 \%, \mathrm{pH} 6$, and organoleptic (brown color, chewy texture, distinctive aroma). At room temperature syneresis 4\%, $\mathrm{pH} 5$, and organoleptic (dark brown color, slightly liquid texture, unpleasant aroma stinging). At hot temperatures syneresis $8 \%, \mathrm{pH} \mathrm{6}$, and organoleptic (brown color, slightly chewy texture, unpleasant aroma). Stability is best kept at cool temperatures $\left(5-15^{\circ} \mathrm{C}\right)$ with syneresis rates of $2 \%, \mathrm{pH} 6$, and organoleptics covering brown color, chewy texture and distinctive scent.
\end{abstract}

Keywords: Avocado seeds, bay leaf, jelly drink, stability. 


\section{PENDAHULUAN}

Biji alpukat (Persea americana Mill.) yang hanya dianggap sebagai ampas, limbah atau bagian yang kurang berguna karena biji dari tanaman alpukat ini memiliki rasa yang pahit.Pemberian infusa biji alpukat $0,315 \mathrm{~g} / \mathrm{kg}$ BB dapat menurukan kadar glukosa darah tikus wistar yang diberi beban glukosa $6,5 \mathrm{~g} / \mathrm{kg}$ BB (Anggraeni, 2006). Kandungan tanin pada biji alpukat memiliki aktivitas antioksidan yang tinggi, sehingga dapat digunakan sebagai sumber antioksidan alami (Malangngi, 2012).

Selain biji alpukat, digunakan juga daun salam (Syzygium polyanthum (Wight) Walp.) yang biasanya digunakan sebagai bumbu masak.Dosis $1,36 \mathrm{mg} / \mathrm{kg}$ BB ekstrak air daun salam mempunyai efek penurunan kadar gula darah pada tikus yang diinduksi dengan glukosa sebesar 5,582\% (Musyrifah et al., 2012).Kandungan senyawa daun salam yaitu alkaloid dan saponin dapat menstimulasi sekresi insulin dari sel beta pankreas (Patel et al., 2012).

Kandungan senyawa tanin dan flavonoid pada kedua tanaman tersebut terbukti bermanfaat untuk pengobatan diabetes, sehingga menjadi pertimbangan untuk menggabungkan keduanya. Pemilihan bentuk sediaan herbal jelly drink karena dapat menutupi rasa pahit pada biji alpukat dan rasa sepat pada daun salam serta saat ini banyak dikembangkan pangan atau minuman fungsional berbasis terapi (food based therapy) yang berasal dari tanaman herbal sehingga banyak disukai oleh masyarakat dari segala kalangan usia.

Jelly drink merupakan salah satu jenis pangan fungsional yang banyak digemari oleh masyarakat luas karena memiliki serat. Jelly drink mengandung serat yang diperoleh dari gelling agent (karagenan) yang digunakan.

Uji stabilitas dilakukan untuk menjamin identitas, kekuatan, kualitas, dan kemurnian produk yang telah diluluskan dan beredar di pasaran, sehingga aman digunakan oleh konsumen (Rismana et al., 2013).

Dengan adanya khasiat antara biji alpukat dan daun salam maka dibuatlah pengembangan formula menjadi sediaan herbal jelly drink campuran ekstrak biji alpukat dan daun salam dengan berbagai variasi karagenan dan dilakukan uji stabilitas meliputi sineresis,

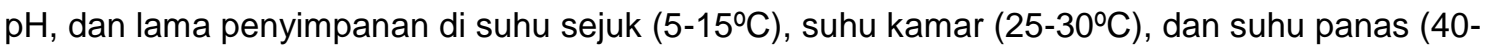
$\left.45^{\circ} \mathrm{C}\right)$.

\section{BAHAN DAN METODE}

\section{Bahan dan Alat}

Bahan yang digunakan diantaranya biji alpukat diperoleh dari penjual jus alpukat di daerah Kabupaten Kuningan, daun salam segar dari pekarangan rumah, sukralosa (Dipa Prasada Husada), garam, potasium sitrat (Dipa Prasada Husada), karagenan jenis kappa (Dipa Prasada Husada), air, dan bahan-bahan untuk skrining fitokimia (serbuk Zn, amil alkohol, asam klorida 2N, perekasi mayer, pereaksi bouchardat, pereaksi dragendorf, $\mathrm{FeCl} 3$, gelatin $1 \%$ )

Alat yang digunakannya yaitu timbangan analitik (newtech), oven (memmert), gelas ukur \& gelas beaker (herma), pipet, blender (philips), waterbath, cawan porselin, ayakan, pisau, panci, penangas air, lemari pendingin (toshiba), inkubator dengan modifikasi, dan botol kemasan.

\section{Jenis Penelitian}

Penelitian ini yaitu penelitian metode eksperimental laboratorium. Diformulasikan dalam bentuk sediaan herbal jelly drink ekstrak biji alpukat dan daun salam. Dilakukan evaluasi meliputi uji sineresis, $\mathrm{pH}$, dan organoleptik sediaan dengan disimpan pada suhu berbeda sehingga dapat menghasilkan produk sediaan herbaljelly drinkyang memiliki khasiat untuk kesehatan. 


\section{Lokasi dan Waktu Penelitian}

Penelitian ini bertempat di Laboratorium STIKes Muhammadiyah Kuningan, dilaksanakan pada bulan Maret - April 2021.

\section{Prosedur Penelitian}

\section{Pembuatan Serbuk Simplisia}

Biji alpukat dari penjual jus yang merupakan limbah pedagang jus alpukat yang berjualan di Kuningan. Dilakukan determinasi di STIKes Muhammadiyah Kuningan.Biji buah alpukat yang telah matang sebanyak $6 \mathrm{~kg}$ dibersihkan, dicuci dengan air mengalir sampai bersih lalu ditiriskan. Biji alpukat dipotong kecil-kecil membujur dengan tebal sekitar $2 \mathrm{~mm}$. Potongan biji alpukat dikeringkan dengan sinar matahari dan di oven pada suhu kurang lebih $50^{\circ} \mathrm{C}$ sampai kering. Lakukan sortasi kering. Simplisia diblender menjadi simplisia serbuk dan diayak menggunakan mesh 30 sehingga diperoleh serbuk. Simplisia disimpan dalam wadah tertutup rapat. Hitung hasil rendemen.

Daun salam segar diperoleh dari pekarangan rumah. Dilakukan determinasi di STIKes Muhammadiyah Kuningan. Daun salam yang dipakai 4 helai setelah pucuk sebanyak $4 \mathrm{~kg}$ dibersihkan dari kotoran-kotoran yang menempel (sortasi basah) lalu dicuci dengan air mengalir sampai bersih, kemudian ditiriskan. Daun salam yang telah bersih dan bebas air pencucian diangin - anginkan dilanjutkan pengeringan di dalam oven pada suhu $50^{\circ} \mathrm{C}$ sampai kering, lalu disortasi kembali dari kotoran yang mungkin tidak hilang saat pencucian. Simplisia kering diblender hingga menjadi simplisia serbuk lalu diayak dengan ayakan mesh 30 lalu ditimbang untuk mendapatkan bobot akhir simplisia, disimpan dalam wadah yang kering dan bersih. Hitung hasil rendemen.

\section{Pembuatan Ekstrak Kental Biji Alpukat}

Sebanyak $1 \mathrm{~kg}$ serbuk simplisia biji alpukat dimasukkan kedalam bejana yang berisi $10 \mathrm{~L}$ air kemudian dipanaskan selama kurang lebih 45 menit atau sampai volume air 2,5 L. Lalu disaring dengan kain flanel untuk kemudian filtratnya dipisahkan (perlakuan pertama). Residu yang didapat kemudian ditambahkan lagi air sebanyak $10 \mathrm{~L}$ dan diperlakukan sama seperti perlakuan pertama sampai 4 kali perlakuan, maka didapatlah volume filtrat sebanyak $10 \mathrm{~L}$ dengan konsentrasi $30 \mathrm{~g} / \mathrm{L}$ (Koffi et al., 2009). Filtrat cair kemudian dibuat ekstrak kental diatas waterbath sehingga didapat ekstrak kental. Hitung hasil rendemen.

\section{Pembuatan Ekstrak Kental Daun Salam}

Dibuat dengan menggunakan metode infus. Sebanyak $50 \mathrm{~g}$ serbuk simplisia daun salam dimasukkan ke dalam panci dengan air $200 \mathrm{~mL}$, kemudian dipanaskan di atas penangas air selama 15 menit terhitung mulai suhu mencapai $90^{\circ} \mathrm{C}$ sambil sesekali diaduk atau sampai air tersisa setengah bagian. Kemudian infus diserkai selagi panas melalui kain batis atau kain flanel, filtrat dimasukkan kedalam labu (perlakuan pertama), residu daun salam ditambah lagi dengan $200 \mathrm{~mL}$ air, selanjutnya dilakukan proses yang sama seperti perlakuan awal (Musyrifah et al., 2012). Filtrat cair yang diperoleh dikentalkan diatas waterbath sehingga didapatkan ekstrak kental. Hitung hasil rendemen.

\section{Skrining Fitokimia Uji Flavonoid}

Sampel sebanyak 0,3 gram ekstrak dimasukkan kedalam tabung reaksi, tambahkan aquadest $2 \mathrm{~mL}$, kemudian ditambahkan $2 \mathrm{mg}$ serbuk $\mathrm{Zn}$ dan $1 \mathrm{~mL}$ asam klorida $2 \mathrm{~N}$. Dipanaskan diatas penangas air dan disaring. Kemudian filtrat ditambahkan $1 \mathrm{~mL}$ amil alkohol lalu dikocok kuat-kuat. Adanya flavonoid akan menyebabkan filtrat berwarna merah, kuning, atau jingga yang dapat ditarik oleh amil alkohol (Fransworth, 1966). 


\section{Uji Alkaloid}

Sampel sebanyak 0,3 gram ekstrak ditambahkan $5 \mathrm{~mL}$ asam klorida $2 \mathrm{~N}$ dan dikocok sampai terbentuk dua lapisan. Lapisan asam (atas) dengan menggunakan pipet dan dibagi menjadi 4 bagian dalam tabung reaksi (Fransworth, 1966).

- Tabung rekasi yang pertama digunakan sebagai blanko.

- Tabung reaksi yang kedua ditambahkan 1-2 tetes pereaksi Mayer, adanya senyawa alkaloid ditandai dengan terbentuknya endapan putih.

- Tabung reaksi yang ketiga ditambahkan 1-2 tetes dengan pereaksi Bouchardat, kemudian diamati ada atau tidaknya endapan.

- Tabung reaksi yang keempat ditambahkan 1-2 tetes dengan pereaksi Dragendorf, Uji Tanin diamati ada atau tidaknya endapan jingga (Fransworth, 1966).

Uji skrining tanin dapat dilakukan dengan 2 metode yaitu dengan $\mathrm{FeCl} 3$ dan gelatin $1 \%$. Sampel sebanyak 0,3 gram ekstrak ditambah dengan $10 \mathrm{~mL}$ air suling, kemudian disaring. Filtrat diencerkan dengan air suling sampai tidak berwarna (Fransworth, 1966).

- Metode FeCl3 yaitu dengan diambil $2 \mathrm{~mL}$ filtrat lalu ditambahkan 3-4 tetes pereaksi $\mathrm{FeCl}$. Terbentuknya warna biru hitam menunjukkan adanya tanin dan polifenol alam.

- Metode gelatin yaitu dengan diambil $2 \mathrm{~mL}$ filtrat lalu ditambahkan 3-4 tetes larutan gelatin 1\%. Adanya endapan putih menunjukkan terdapat tanin (Fransworth, 1966).

\section{Uji Saponin}

Sampel sebanyak 0,3 gram ekstrak dimasukkan ke dalam tabung reaksi, kemudian ditambahkan dengan $10 \mathrm{~mL}$ air dan panaskan. Setelah dingin tabung reaksi dikocok kuat selama beberapa menit. Pembentukkan busa sekurang-kurangnya setinggi $1 \mathrm{~cm}$ dan persisten selama beberapa menit dan tidak hilang dengan penambahan beberapa tetes asam klorida 2N, menunjukkan adanya saponin (Fransworth, 1966).

\section{Formulasi}

Tabel 1. Formulasi Pembuatan Herbal Jelly Drink Ekstrak Biji Alpukat Dan Daun Salam

\begin{tabular}{lccc}
\hline \multicolumn{1}{c}{ Bahan } & Formula 1 & Formula 2 & Formula 3 \\
\hline Ekstrak Biji Alpukat & $32,50 \%$ & $32,50 \%$ & $32,50 \%$ \\
Ekstrak Daun Salam & $0,10 \%$ & $0,10 \%$ & $0,10 \%$ \\
Sukralosa & $13,00 \%$ & $13,00 \%$ & $13,00 \%$ \\
Garam & $0,10 \%$ & $0,10 \%$ & $0,10 \%$ \\
Potasium Sitrat & $0,15 \%$ & $0,15 \%$ & $0,15 \%$ \\
Karagenan & $0,20 \%$ & $0,30 \%$ & $0,40 \%$ \\
Air & $100 \mathrm{~mL}$ & $100 \mathrm{~mL}$ & $100 \mathrm{~mL}$ \\
\hline
\end{tabular}

Setiap formula masing-masing dibuat @ 100 mL

\section{Pembuatan Sediaan Herbal Jelly Drink Ekstrak Biji Alpukat Dan Daun Salam}

Tahap awal pembuatan herbal jelly drink yaitu siapkan alat dan bahan. Dilakukan penimbangan bahan menurut formula yang sudah ditentukan yaitu sukralosa, kappa karagenan, potasium sitrat, dan garam.

Pencampuran bahan sesuai dengan formula yang telah dirancang, dengan perbandingan konsentrasi karagenan berbeda-beda pada setiap perlakuan. Pembuatan larutan jelly dengan pencampuran semua bahan dan dipanaskan sampai $\pm 70^{\circ} \mathrm{C}$ sekitar $4-5$ menit sambil terus diaduk. Kemudian dihilangkan uap panasnya dan dituang ke dalam botol ukuran $100 \mathrm{~mL}$, lalu didiamkan hingga membentuk jelly. 


\section{Evaluasi Sediaan}

Uji stabilitas terhadap sediaan herbal jelly drink dilakukan agar dapat diketahui kualitasnya dengan disimpan pada suhu sejuk $\left(5-15^{\circ} \mathrm{C}\right)$, suhu kamar $\left(25^{-30^{\circ}} \mathrm{C}\right)$, dan suhu panas $\left(40-45^{\circ} \mathrm{C}\right)$ sehingga dapat menghasilkan produk inovasi herbal dengan stabilitas yang baik, memiliki khasiat untuk kesehatan.

\section{Sineresis}

Menurut (Imeson, 1992) dilakukan dengan memasukkan jelly drink ke dalam cup plastik dengan berat yang sama tiap perlakuan dan disimpan selama hari ke-1, 7, 14, dan 21 di penyimpanan suhu berbeda dengan mengambil air yang terpisah dari jelly drink kemudian ditimbang beratnya. Menghitung tingkat sineresis dengan rumus :

Tingkat sineresis $=(($ berat awal $(\mathrm{g})-($ berat akhir $(\mathrm{g}))$

(berat awal $(g)) \times 100 \%$

Keterangan :

Berat awal : berat jelly drink dalam cup

Berat akhir : berat jelly drink dalam cup setelah dilakukan pemisahan air yang terlepas dari sistem gel

\section{$\mathrm{pH}$}

Pada penelitian ini menggunakan $\mathrm{pH}$ indikator universal. Analisis selama hari ke-1, 7, 14, dan 21 di penyimpanan suhu berbeda. Penggunaannya sangat sederhana, sehelai kertas indikator dicelupkan kedalam larutan yang akan diukur $\mathrm{pH}$ nya. Kemudian dibandingkan dengan peta warna yang tersedia. Tiap warna mewakili nlai $\mathrm{pH}$ yang berbeda. Catat angka pH yang sesuai (Santoso, 2017).

\section{Organoleptik}

Parameter diuji terhadap warna, tekstur, dan aroma selama penyimpanan. Penyimpanan dilakukan selama 21 hari dengan rentang pengamatan setiap 3 hari.

\section{Analisis Data}

Data yang diperoleh dari hasil pengujian sineresis dan $\mathrm{pH}$ kemudian diolah menggunakan Microsoft Excel 2013 untuk mendapatkan rata-rata. Hasil dari pengamatan sineresis, $\mathrm{pH}$, dan organoleptik sediaan pada suhu sejuk (5-15을 suhu panas $\left(40-45^{\circ} \mathrm{C}\right)$ selama penyimpanan data disajikan dalam bentuk tabel. Dianalisis secara deskriptif.

\section{HASIL DAN PEMBAHASAN}

\section{Determinasi}

Hasil determinasi yang dilakukan di STIKes Muhammadiyah Kuningan menunjukkan sebagaimana yang ditunjukkan pada Tabel 2 .

Tabel 2. Hasil Determinasi Biji Alpukat Dan Daun Salam

\begin{tabular}{ccc}
\hline Nama Tanaman & Jenis & Suku \\
\hline Biji Alpukat & Persea americana Mill. & Lauraceae \\
\hline Daun Salam & Syzygium polyanthum (Wight)Walp. & Myrtaceae \\
\hline
\end{tabular}

\section{Serbuk Simplisia}

Hasil rendemen serbuk simplisia biji alpukat dan daun salam yang diperoleh menunjukkan sebagaimana yang ditunjukkan pada Tabel 3 . 
Tabel 3. Hasil Serbuk SimplisiaBiji Alpukat Dan Daun Salam

\begin{tabular}{cccc}
\hline Tanaman & Berat Tanaman Segar & Serbuk Diperoleh & Rendemen \% \\
\hline Biji Alpukat & $6000 \mathrm{~g}$ & $2000 \mathrm{~g}$ & $33,33 \%$ \\
\hline Daun Salam & $4000 \mathrm{~g}$ & $500 \mathrm{~g}$ & $12,50 \%$ \\
\hline
\end{tabular}

\section{Ekstrak Kental}

Hasil ekstrak kental biji alpukat dan daun salam yang diperoleh dari ekstraksi dekoksi dan infus, dapat dilihat pada Gambar 1.

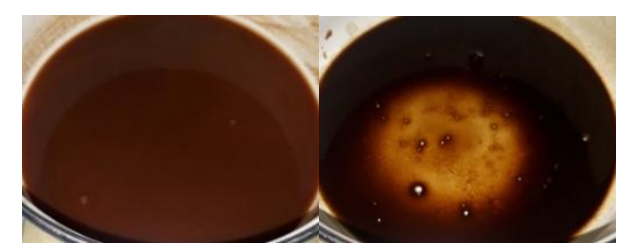

Gambar 1. Ekstrak Biji Alpukat Dan Daun Salam

Hasil rendeman yang diperoleh dapat dilihat pada Tabel 4.

Tabel 4. Hasil Ekstrak Kental Biji Alpukat Dan Daun Salam

\begin{tabular}{cccc}
\hline Tanaman & Serbuk & Ekstrak Diperoleh & Rendemen \% \\
\hline Biji Alpukat & $1000 \mathrm{~g}$ & $382 \mathrm{~g}$ & $38,20 \%$ \\
\hline Daun Salam & $50 \mathrm{~g}$ & $17 \mathrm{~g}$ & $34,00 \%$ \\
\hline
\end{tabular}

\section{Skrining Fitokimia}

Hasil penelitian menunjukkan bahwa ekstrak biji alpukat dan daun salam mengandung adanya senyawa flavonoid, alkaloid, saponin, dan tanin sebagaimana pada Tabel 5.

Tabel 5. Skrining Fitokimia Ekstrak Biji Alpukat Dan Daun Salam

\begin{tabular}{ccccc}
\hline \multirow{2}{*}{ Sampel } & \multicolumn{5}{c}{ Golongan Senyawa } \\
& Flavonoid & Alkaloid & Saponin & Tanin \\
\hline Ekstrak Kental Biji Alpukat & + & + & + & + \\
\hline Ekstrak Kental Daun Salam & + & + & + & + \\
\hline
\end{tabular}

\section{Sediaan Herbal Jelly Drink}

Sediaan herbal jelly drink ekstrak biji alpukat dan daun salam dengan variasi karagenan (F1: 0,20\%; F2: 0,30\%; F3: 0,40\%) dapat diformulasikan dengan baik. Jelly yang terbentuk mudah dihisap dengan bantuan sedotan. Hasil sediaan jelly drink dapat dilihat pada Gambar 2.

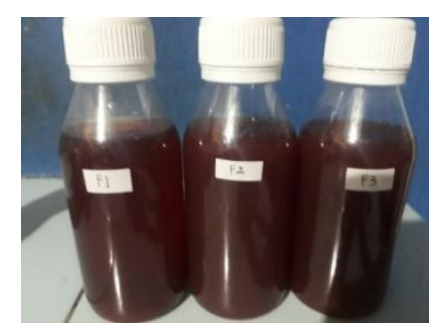

Gambar 2. Herbal Jelly Drink Ekstrak Biji Alpukat Dan Daun Salam 


\section{Evaluasi Sediaan}

\section{Sineresis}

Hasil penelitian menunjukkan bahwa semakin semakin tinggi konsentrasi karagenan yang digunakan maka tingkat sineresis jelly drink ekstrak biji alpukat dan daun salam semakin rendah. Waktu penyimpanan yang semakin lama menyebabkan sineresis semakin tinggi. Rata-rata sineresis selama 21 hari pada suhu sejuk $\left(5-15^{\circ} \mathrm{C}\right)(\mathrm{F} 1: 4 \% ; \mathrm{F} 2$ : $2 \%$; F3: $1 \%)$, suhu kamar $\left(25-30^{\circ} \mathrm{C}\right)(\mathrm{F} 1: 6.3 \%$; F2: $4 \%$; F3: $2 \%)$ dan suhu panas (40$\left.45^{\circ} \mathrm{C}\right)(\mathrm{F} 1: 9 \%$; $\mathrm{F} 2: 8 \%$; F3: $5 \%$ ). Hasil pengamatan sineresis dapat dilihat sebagaimana pada Tabel 6.

Tabel 6. Evaluasi Sineresis Sedian

\begin{tabular}{ccccc}
\hline Hari & Sampel & Suhu Sejuk & Suhu Kamar & Suhu Panas \\
\hline \multirow{2}{*}{1} & F1 & $0 \%$ & $0 \%$ & $0 \%$ \\
& F2 & $0 \%$ & $0 \%$ & $0 \%$ \\
& F3 & $0 \%$ & $0 \%$ & $0 \%$ \\
\hline \multirow{2}{*}{7} & F1 & $2,5 \%$ & $5 \%$ & $10 \%$ \\
& F2 & $0 \%$ & $0 \%$ & $5 \%$ \\
& F3 & $0 \%$ & $0 \%$ & $2,5 \%$ \\
\hline \multirow{2}{*}{14} & F1 & $5 \%$ & $10 \%$ & $12,5 \%$ \\
& F2 & $2,5 \%$ & $7,5 \%$ & $10 \%$ \\
& F3 & $0 \%$ & $2,5 \%$ & $5 \%$ \\
\hline \multirow{2}{*}{21} & F1 & $10 \%$ & $10 \%$ & $15 \%$ \\
& F2 & $5 \%$ & $7,5 \%$ & $12,5 \%$ \\
\hline
\end{tabular}

pH

Hasil penelitian menunjukkan selama penyimpanan jelly drink mengalami penurunan $\mathrm{pH}$. Rata-rata $\mathrm{pH}$ selama 21 hari pada suhu sejuk $\left(5-15^{\circ} \mathrm{C}\right)(\mathrm{F} 1: 7$; F2: 6 ; F3: 6), suhu kamar $\left(25-30^{\circ} \mathrm{C}\right)\left(\mathrm{F} 1: 4\right.$; F2: 5 ; F3: 4) dan suhu panas $\left(40-45^{\circ} \mathrm{C}\right)(\mathrm{F} 1: 5$; F2:6 ; F3: 5). Penurunan $\mathrm{pH}$ terjadi diduga karena adanya aktivitas mikroorganisme. Dapat dilihat pada Tabel 7.

Tabel 7. Evaluasi pH Sediaan

\begin{tabular}{ccccc}
\hline Hari & Sampel & Suhu Sejuk & Suhu Kamar & Suhu Panas \\
\hline \multirow{3}{*}{1} & F1 & 7 & 6 & 6 \\
& & & & 7 \\
& F2 & 6 & 7 & 6 \\
\hline \multirow{3}{*}{7} & F3 & 6 & 6 & 5 \\
& F1 & 7 & 4 & 6 \\
& F3 & 6 & 6 & 5 \\
\hline \multirow{3}{*}{14} & F1 & 6 & 4 & 4 \\
& F2 & 7 & 3 & 5 \\
\hline \multirow{2}{*}{21} & F3 & 6 & 4 & 3 \\
& F1 & 6 & 4 & 4 \\
& F2 & 7 & 3 & 4 \\
\hline
\end{tabular}

\section{Organoleptik}

Hasil penelitian pada pengamatan organoleptik menunjukkan adanya perubahan warna, tekstur, dan aroma terutama pada sediaan yang disimpan pada suhu kamar (25- 
$30^{\circ} \mathrm{C}$ ). Perubahan tersebut diduga karena adanya aktivitas mikroorganisme pada sediaan yang menjadi tempat tumbuhnya mikroorganisme.

Sediaan jelly drink yang disimpan disuhu sejuk $\left(5-15^{\circ} \mathrm{C}\right)$ sangat stabil selama penyimpanan dalam waktu 21 hari memiliki warna (F1, F2, F3 : coklat), tekstur (F1: sedikit cair ; F2: kenyal ; F3: kenyal) dan aroma (F1, F2, F3 : khas). Dapat dilihat pada Tabel 8.

Tabel 8. Evaluasi Organoleptik Sediaan

\begin{tabular}{|c|c|c|c|c|c|c|c|c|c|c|}
\hline \multirow{3}{*}{$\begin{array}{l}\text { Hari } \\
\mathrm{Ke}-\end{array}$} & \multirow{3}{*}{ Sampel } & \multicolumn{9}{|c|}{ Penyimpanan Organoleptik } \\
\hline & & \multicolumn{3}{|c|}{ Suhu Sejuk } & \multicolumn{3}{|c|}{ Suhu Kamar } & \multicolumn{3}{|c|}{ Suhu Panas } \\
\hline & & Warna & Tekstur & Aroma & Warna & Tekstur & Aroma & Warna & Tekstur & Aroma \\
\hline \multirow{3}{*}{3} & F1 & C & $\mathrm{K}$ & $\mathrm{K}$ & C & $\mathrm{K}$ & $\mathrm{K}$ & C & $\mathrm{K}$ & $\mathrm{K}$ \\
\hline & F2 & C & $\mathrm{K}$ & K & C & $\mathrm{K}$ & $\mathrm{K}$ & C & $\mathrm{K}$ & $\mathrm{K}$ \\
\hline & F3 & C & $\mathrm{K}$ & K & C & $\mathrm{K}$ & $\mathrm{K}$ & C & $\mathrm{K}$ & $\mathrm{K}$ \\
\hline \multirow{3}{*}{6} & F1 & C & SK & $\mathrm{K}$ & C & SK & TS & C & SK & $\mathrm{K}$ \\
\hline & F2 & C & $\mathrm{K}$ & K & C & $\mathrm{K}$ & TS & C & $\mathrm{K}$ & $\mathrm{K}$ \\
\hline & F3 & C & $\mathrm{K}$ & K & C & $\mathrm{K}$ & TS & C & $\mathrm{K}$ & $\mathrm{K}$ \\
\hline \multirow{3}{*}{9} & F1 & C & SK & $\mathrm{K}$ & C & SK & TS & C & SK & $\mathrm{K}$ \\
\hline & F2 & C & $\mathrm{K}$ & K & C & $\mathrm{K}$ & TS & C & SK & $\mathrm{K}$ \\
\hline & F3 & C & $\mathrm{K}$ & K & C & $\mathrm{K}$ & TS & C & $\mathrm{K}$ & $\mathrm{K}$ \\
\hline \multirow{3}{*}{12} & $\mathrm{~F} 1$ & C & SK & $\mathrm{K}$ & C & SC & TSM & C & SC & $\mathrm{K}$ \\
\hline & F2 & C & $\mathrm{K}$ & K & $\mathrm{CG}$ & SK & TSM & C & SK & $\mathrm{K}$ \\
\hline & F3 & C & $\mathrm{K}$ & K & CG & SK & TSM & C & SK & $\mathrm{K}$ \\
\hline \multirow{3}{*}{15} & F1 & C & SK & $\mathrm{K}$ & CG & SC & TSM & $C$ & SC & $\mathrm{K}$ \\
\hline & F2 & C & $\mathrm{K}$ & K & CG & SK & TSM & $C$ & SK & $\mathrm{K}$ \\
\hline & F3 & C & $\mathrm{K}$ & K & CG & SK & TSM & CG & SK & $\mathrm{K}$ \\
\hline \multirow{3}{*}{18} & F1 & C & SK & $\mathrm{K}$ & CG & SC & TSM & $C$ & SC & $\mathrm{K}$ \\
\hline & F2 & C & $\mathrm{K}$ & $\mathrm{K}$ & $\mathrm{CG}$ & SK & TSM & C & SK & $\mathrm{K}$ \\
\hline & F3 & C & $\mathrm{K}$ & $\mathrm{K}$ & CG & SK & TSM & CG & SK & $\mathrm{K}$ \\
\hline \multirow{3}{*}{21} & $\mathrm{~F} 1$ & C & SK & $\mathrm{K}$ & CG & SC & TSM & $\mathrm{C}$ & SC & TS \\
\hline & F2 & C & $\mathrm{K}$ & K & $\mathrm{CG}$ & SK & TSM & $\mathrm{C}$ & SK & TS \\
\hline & F3 & C & $\mathrm{K}$ & $\mathrm{K}$ & CG & SK & TSM & CG & SK & TS \\
\hline
\end{tabular}

Keterangan :

Warna :

CM : Coklat Muda; C : Coklat; CG : Coklat Gelap

Tekstur :

K : Kenyal; SK : Sedikit Kenyal; SC : Sedikit Cair

Aroma :

K : Khas; TS : Tidak Sedap; TSM : Tidak Sedap Menyengat

\section{SIMPULAN}

Ekstrak biji alpukat dan daun salam dapat diformulasikan dengan baik menjadi sediaan jelly drink dengan konsentrasi karagenan $(0,20 \% ; 0,30 \% ; 0,40 \%)$. Sediaan dengan konsentrasi karagenan $0,30 \%$ terbentuk jelly yang memiliki tekstur dan konsistensi yang baik. Sediaan ini mempunyai stabilitas paling baik selama 21 hari yang disimpan pada suhu sejuk (5$15^{\circ} \mathrm{C}$ ) dengan tingkat sineresis $2 \%, \mathrm{pH} 6$, dan organoleptik meliputi warna coklat, tekstur kenyal, dan aroma yang khas.

\section{REFERENSI}

Anggraeni, A. D. 2006. Pengaruh Pemberian Infusa Biji Alpukat (Persea americana Mill.) Terhadap Kadar Glukosa Darah Tikus Wistar Yang Diberi Beban Glukosa [Karya Tulis Ilmiah] Fakultas Kedokteran Universitas Diponegoro. Semarang.

Fransworth, N. R. 1996. Biological and Phytochemical Screening of Plants. Journal of Pharmaceutical Science, 199655 (3).

Imeson, A. 1992. Thickening and Gelling Agents for Food. Blackie Academic \& Profesional, New York. 
Koffi, N., Ernest, A.K., Dodiomon, S. 2009. Effect Of Aqueous Extract Of Persea americana Seeds On The Glycemia Of Diabetic Rabbits. European Journal of Scientific Research. ISSN : 1450-216X 26 (3) (2009). 12.

Malangngi, L. P., Meiske, S. S., \& Jessy, J. E. P. 2012. Penentuan Kandungan Tanin Dan Uji Aktivitas Antioksidan Ekstrak Biji Buah Alpukat (Persea americana Mill.) Jurnal MIPA UNSRAT ONLINE, 1(1): 5-10

Musyrifah, S., Bekti \& Fauzia. 2012. Pastiles Daun Salam (Eugenia polyantha W). Berkala Ilmiah Mahasiswa Farmasi Indonesia. Volume 1 No.1. Universitas Gajah Mada : Yogyakarta.

Patel, D., Kumar, L., Laloo, D., \& Hemalatha, S. 2012. Natural Medicine From Plant Source Used For Therapy Of Diabetes Mellitus : An Overview Of Its Pharmacological Aspects. Asian Pacific Journal Of Tropical Disease, 239-250.

Rismana, E., Kusumaningrum, S., Rosidah I., Nizar., \& Yulianti E. 2013. Pengujian Stabilitas Sediaan Antiacne Berbahan Baku Aktif Nanopartikel Kitosan / Ekstrak Manggis Pegagan. Buletin Penelitian Kesehatan Vol.41 No.4 207-216.

Santoso, R. B. 2017. Citra Digital Deteksi pH Larutan Berdasarkan Warna Kertas Indikator Universal Menggunakan Metode Euclidean Distance [Thesis] Universitas 17 Agustus 1945. 